\title{
AS REDES SOCIAIS COMO MEIO DE PROVA NO PROCESSO CIVIL
}

\author{
Juliana Batista Costa* \\ Professora Mestra Daniela Pozza Batista**
}

\section{RESUMO}

Este trabalho pretende compreender a evolução social diante da era tecnológica dentro do processo civil, especificamente na produção de provas por meio das redes sociais. As redes sociais fazem parte da vida das pessoas, em um contexto social no qual a sociedade vive conectada, expondo suas atividades cotidianas em uma rede com milhões de usuários, é por meio dessas plataformas que se pode alcançar a informação sobre qualquer coisa, inclusive sobre dados pessoais. No decorrer do trabalho serão observadas todas as fases processuais até o momento da fase probatória, levantando as suas características, bem como o conceito de prova, seus meios e formas de produção. A mutação da sociedade por meio da internet será respaldada com o estudo de Leis específicas, como o Marco Civil da Internet e outras leis referentes à política de privacidade estabelecida na plataforma de comunicação para que, assim, haja a compreensão da corriqueira existência de prints das redes sociais nos processos, utilizadas como prova documental eletrônica e a forma de adaptação e recepção tanto do ordenamento jurídico quanto do Poder Judiciário dessa nova modalidade de prova.

Palavras-chave: Prova. Fase Probatória. Redes Sociais. Privacidade. Internet. Processo Civil. Proteção de Dados.

\section{LAS REDES SOCIALES COMO MEDIOS DE PRUEBA EM EL PROCESO CIVIL}

\section{RESUMEN}

Este trabajo tiene como objetivo entender la evolución social frente a la era tecnológica dentro del proceso civil, específicamente en la producción de evidencia a través de las redes sociales. Las redes sociales forman parte de la vida de las personas, en un contexto social donde la sociedad vive conectada, exponiendo sus actividades diarias en una red con millones de usuarios, es a través de estas plataformas que se puede llegar a la información sobre cualquier cosa, datos personales. Durante el trabajo, se observarán todas las fases procesales hasta el momento de la fase probatoria, elevando sus características, así como el concepto de prueba, sus medios y formas de producción. La mutación de la sociedad a través de Internet estará respaldada por el estudio de leyes

* Bacharel em Direito pela Universidade Metodista de São Paulo.

** Mestra em Direitos Difusos e Coletivos pela Universidade Metropolitana de Santos - UNIMES. Especialista em Direito Processual pela Universidade Paulista - UNIP. Advogada. Professora Universitária e Coordenadora do Escritório de Assistência Judiciária. 
específicas como el Marco Civil de Internet y otras leyes de política de privacidad establecidas en la plataforma de comunicación para que se comprenda la exactitud existencia de prints de redes sociales en los procesos, utilizadas como prueba documental electrónica y forma de adaptación y recepción tanto del derecho como del poder judicial de este nuevo modo de prueba.

Palabras-clave: Prueba. Fase probatoria. Redes Sociales. Privacidad. Internet. Procedimientos Civiles. Protección de datos.

\section{INTRODUÇÃO}

O surgimento da internet expandiu e facilitou o acesso a informações e à comunicação, sendo hoje a principal forma de interação da sociedade. Entre tais tecnologias que a cada dia se intensificam no nosso cotidiano, o Poder Judiciário se deparou com mais uma mutação da sociedade, encontrando novas possibilidades e desafios processuais.

Ao fazer o cadastro em uma rede social, dados e informações pessoais do usuário são solicitados para a criação de um perfil. Fato é que, no momento de cadastro, uma política de privacidade é apresentada, porém a grande maioria dos usuários desconhece o seu conteúdo.

Diante da frequente comunicação entre as pessoas via aplicativos ou sites, sejam conversas de conteúdo pessoal ou comercial, começaram a surgir fotos, ou como são popularmente conhecidos prints, de conversas ou postagens nas redes sociais como forma de provar o alegado em demandas processuais. Surge então, uma nova prova. Os documentos eletrônicos dominam a maioria das petições, com objetivo de demonstrar fatos.

A Constituição Federal, em seu artigo $5^{\circ}$, inciso $X$, declara que o direito à privacidade é inviolável e deve ser assegurado a todos, sem distinções. A garantia constitucional propicia aos navegadores da internet o direito à privacidade, principalmente de dados fornecidos às redes. Porém, os acessos aos perfis são sensíveis, ainda mais quando o perfil do usuário se torna público por sua própria escolha.

Sabendo-se que os documentos eletrônicos podem ser alterados ou editados, buscamos uma forma de dar veracidade a esse tipo de prova para que haja sua aceitação em juízo, que tem recebido inúmeros documentos eletrônicos dentro da fase probatória do processo, fase esta que é imprescindível para o devido processo legal e o livre convencimento motivado do juiz.

\section{PROCESSO CIVIL}

O direito processual civil tem natureza pública, tendo em vista que exerce a função jurisdicional para que as normas sejam aplicadas pelo Estado. Ou seja, é a aplicação do direito na prática.

A provocação do Estado-juiz é de caráter essencial para a existência do processo. Já que jurisdição precisa ser provocada para ser exercida, não há como o 
Poder Judiciário ter ciência de um conflito se este não for informado a ele. Por isso, cabe ao indivíduo que teve seu direito lesado, levar o conflito ao conhecimento do órgão competente.

Temos então, o processo de conhecimento, momento em que ocorre a apresentação da situação que motivou o litígio ao juiz. Uma vez ciente do conflito, o Estado-juiz deve citar o réu em respeito ao princípio do contraditório e ampla defesa, chamando-o ao processo e formando a triangularização do processo.

No processo de conhecimento, ocorre toda a produção de provas, a oitiva das partes e testemunhas e o conhecimento dos fatos, a fim de que seja possível a aplicação correta do direito ao caso concreto, e finalmente proferir a devida sentença.

O processo civil é dividido em fases, sendo estas: fase postulatória, fase ordinatória e fase probatória. Se faz necessária uma breve análise dessas fases para maior compreensão de todo o procedimento do processo civil.

A fase postulatória é aquela na qual as partes, autor e réu, podem fazer suas alegações e pedidos, e por isso a petição inicial é o instrumento que inicia o processo.

O autor deve se atentar aos requisitos intrínsecos da petição inicial que estão estabelecidos no artigo 319 do Código de Processo Civil. Neste momento, a parte deve indicar quais os meios de prova que pretende utilizar para confirmar a veracidade dos fatos que alegou. As provas podem ser documentais, que no caso já podem acompanhar a peça inicial, requerer a prova pericial que necessita de conhecimentos técnicos, lembrando que todas as provas devem ter justificação para seu requerimento.

Após o réu apresentar a contestação, sua forma de defesa das alegações iniciais do autor, dá-se por encerrada a fase postulatória, iniciando a próxima fase.

A fase ordinatória também denominada como fase saneadora, tem como objetivo organizar o processo, verificando as alegações da inicial e da defesa, os pedidos preliminares, a existência de revelia, causas de extinção da ação e, ainda, a verificação dos pontos controvertidos para que sejam fixados e esclarecidos na próxima fase. É o momento em que o juiz mapeará o processo, distinguir qual será o caminho para a solução da lide e os passos para chegar até o objetivo. Feito isso, o processo seguirá para próximas fases, de acordo com as diligências designadas pelo juiz.

Findada a fase de saneamento do processo, entende-se que o processo está devidamente organizado e apto para a fase seguinte, a fase probatória ou instrutória.

Nesta fase, as partes terão que produzir provas legais e moralmente legítimas para que a sua pretensão seja acolhida. $O$ juiz pode requerer diligências para que quaisquer dúvidas que eventualmente restarem no processo sejam elucidadas para uma decisão justa. Cabe ao juiz, na fase probatória, estar ativo no processo para acompanhar as provas e alegações.

Humberto Theodoro Júnior dissertou sobre o princípio do livre convencimento e a função do juiz nesta fase: 
sujeitos, de forma que tanto as partes, como o juiz, contraem o dever de cooperar na formação do provimento que corresponda à justiça prometida pela Constituição. (THEODORO JUNIOR, 2018, p. 34).

Como descrito no próprio princípio, o conjunto probatório será a base para o livre convencimento motivado do juiz para sentenciar a favor da parte que lhe pareceu prejudicada, buscando a justiça. Importante ressaltar que o juiz deve prezar pela imparcialidade e sua decisão deve sempre ser fundamentada nos limites dos termos da lide.

Após a apresentação de todas as provas pertinentes à lide, dá-se início à fase decisória, onde o juiz proferirá sentença. O juiz fará uso do conjunto probatório colhido ao longo de todo o trâmite processual para formar seu convencimento em busca da verdade real e da mais lídima, se tornando o motivo pelo qual as provas são tão importantes dentro do processo.

\section{PROVAS}

A produção de provas no processo tem como objetivo confirmar a veracidade de um fato para que haja o convencimento do juiz. O exercício da produção de prova pode ser desempenhado pelos sujeitos do processo no momento em que queiram provar a existência de um fato.

O Código de Processo Civil, em seu artigo 369, garante às partes o direito à prova:

As partes têm o direito de empregar todos os meios legais, bem como os moralmente legítimos, ainda que não especificados neste Código, para provar a verdade dos fatos em que se funda o pedido ou a defesa e influir eficazmente na convicção do juiz (BRASIL. CÓDIGO DE PROCESSO CIVIL, 2015).

O direito à prova está respaldado pelo princípio do contraditório e ampla defesa que democratiza o processo, garantindo à parte o direito de produzir as provas necessárias para o convencimento do juiz.

O sistema jurídico tem como preceito ser dever da parte que alega um fato, prová-lo juridicamente, conforme exposto no artigo 373 do Código de Processo Civil, dever esse conhecido como "ônus da prova". Então, caso não haja prova suficiente de um fato e a parte incumbida de prová-lo não o fizer, o julgamento será contrário às suas pretensões.

Diante da diversidade de provas que podem ser produzidas no processo, foi necessária a criação de uma classificação para que fossem enquadradas nos requisitos legais.

Quanto ao sujeito, pode ser pessoal aquela prestada por uma pessoa a respeito de um fato, como a oitiva de testemunhas ou o depoimento pessoal das partes.

Quanto à forma, a prova oral é colhida verbalmente, como os depoimentos das partes e das testemunhas, e as escritas são aquelas redigidas, como os documentos e perícias. 
As provas são classificadas de diversas formas, ainda que não respondam a uma ordem hierárquica. Todas têm o mesmo objetivo: convencer o juiz de suas alegações e apurar a veracidade dos fatos alegados.

Os meios de prova mencionados pelo Código de Processo Civil no artigo 369, são os mecanismos em que as partes podem utilizar para obter as provas necessárias, juridicamente e moralmente admitidas.

Embora o artigo tenha dado direito às partes de empregarem além dos meios legais, meios moralmente legítimos que não foram classificados no Código devem ter como objetivo fundamentar as alegações para o convencimento do juiz.

\subsection{PROVA DOCUMENTAL}

A prova documental é a representação do fato de forma material, ou seja, somente documentos escritos que foram registrados em papel são admitidos.

\footnotetext{
Em sentido lato, documento compreende não apenas os escritos, mas toda e qualquer coisa que transmita diretamente um registro físico a respeito de algum fato, como os desenhos, as fotografias, as gravações sonoras, filmes cinematográficos etc. Mas, em sentido estrito, quando se fala da prova documental, cuida-se especificamente dos documentos escritos, que são aqueles em que o fato vem registrado pela palavra escrita, em papel ou outro material adequado (THEODORO JUNIOR, 2018, p. 987).
}

A autenticidade dos documentos é uma de suas características fundamentais, o que confirma o conteúdo do documento com a realidade dos fatos. Por esta razão, os documentos públicos são presumidamente autênticos, tendo em vista que são dotados de fé pública.

Os documentos particulares não são dotados de presunção de veracidade. Para que haja a comprovação da autenticidade, é necessário que o documento seja autenticado, ainda assim essa diligência não é obrigatória.

A finalidade dos documentos é compor o conjunto probatório do processo para que, no momento da apreciação, o magistrado compreenda o contexto entre o fato e a prova.

Os documentos apresentados podem ser informais ou formais, em sua forma original ou cópia, valendo-se do princípio da autenticidade mencionado anteriormente.

Os documentos públicos são aqueles advindos de repartições públicas e os particulares são feitos pela própria parte, assim está determinado no artigo 405 do Código de Processo Civil: “Art.405. O documento público faz prova não só da sua formação, mas também dos fatos que o escrivão, o chefe de secretaria, o tabelião, ou o servidor declarar que ocorreram em sua presença." (BRASIL. CÓDIGO DE PROCESSO CIVIL, 2015).

Quando feitos genuinamente, todos os documentos públicos têm presunção de veracidade juris tantum, e em razão da fé pública outorgada aos órgãos competentes. É de suma importância saber diferenciar documento de instrumento, documento é o registro material dos fatos, já o instrumento é um meio de produzir prova futura, como por exemplo, o recibo de aluguel é instrumento da quitação da dívida. 
O documento utilizado como prova pode ser apresentado em sua forma original ou em cópia e terá a mesma eficácia. Porém, se o documento for autêntico, há maior possibilidade de convencer sobre suas informações.

No sistema processual brasileiro não existe hierarquia entre as provas, o juiz deve examinar o conjunto probatório formando seu convencimento com base naquilo que lhe fora apresentado conforme disposto no artigo 371 do Código de Processo Civil: “Art. 371. O juiz apreciará a prova constante dos autos, independentemente do sujeito que a tiver promovido, e indicará na decisão as razões da formação de seu convencimento." (BRASIL, CÓDIGO DE PROCESSO CIVIL, 2015).

Entende-se que há duas características no documento: o fato representativo, que é o próprio documento em seu aspecto material, e o fato que ele representa. Ainda que o processo admita documento particular e não tenha nível hierárquico entre as provas quando exigido o documento público, este não pode ser substituído por nenhuma prova.

\subsubsection{ATA Notarial}

É importante ressaltar que a ata notarial é um documento público registrado por tabelião, que verifica e atesta a existência de um fato, garantindo a publicidade, a autenticidade, e a segurança jurídica. O registro da ata deve ser feito por tabelião ou notário, pessoa que detenha fé pública.

Podem ser registrados em sede de ata notarial, além dos fatos verificados pelo tabelião, dados obtidos pela internet, como conversas de WhatsApp ou postagens do Facebook por exemplo. Para assegurar o conteúdo de página da internet, o tabelião consulta o endereço eletrônico do computador, anotando em ata o dia e a hora e descrevendo as informações apresentadas pela página, podendo contar ainda o histórico de páginas acessadas até chegar à página objeto da prova.

A ata notarial não é escritura pública, uma vez que a escritura confirma negócios jurídicos e declarações de vontade, já a ata notarial atesta ou documenta a existência de um fato, e também podem constar em ata imagens ou sons gravados em arquivos eletrônicos e, por ser um documento dotado de fé pública, detém presunção de veracidade juris tantum, pois não há garantia de que um fato atestado em ata notarial seja incontestável ou que possa gerar a procedência ou improcedência do pedido, pois, ainda que presumida sua veracidade, admite-se prova em contrário.

Tendo exposto todas as especificações da prova, abordaremos o uso das redes sociais como meio de prova no processo civil, tema central deste trabalho.

\section{REDES SOCIAIS COMO MEIO DE PROVA NO PROCESSO CIVIL}

A sociedade passou por inúmeras mudanças no decorrer dos anos, acarretando grandes modificações na forma de pensamento, comportamento e vivência.

No âmbito do Poder Judiciário, as mudanças foram consideravelmente perceptíveis, os fóruns abarrotados de papéis foram substituídos por computadores que concentram os processos, que agora são distribuídos eletronicamente, até mesmo os processos físicos estão sendo digitalizados. 
A praticidade e a acessibilidade foram grandes avanços que a tecnologia trouxe ao processo em todas as esferas. A internet trouxe uma enorme carga de informações à sociedade que, até hoje, não consegue dar conta de tudo que é apresentado pela rede.

Além da informação e praticidade de acesso, a internet trouxe plataformas de lazer e compartilhamento de momentos: as redes sociais. Exemplos disso são o Facebook, o Instagram e o WhatsApp, aplicativos de conversa e compartilhamento de diversos conteúdos, contando hoje com milhares de usuários.

Ocorre que muitas informações são compartilhadas nessas redes e, diante desse fato, tornou-se corriqueira a presença de registros feitos pelo usuário nas redes sociais, como prova no processo civil, fotos, textos, informações pessoais e até mesmo registros de localização que podem ser obtidos por estes aplicativos.

As redes sociais estão inclusas no cotidiano da sociedade e com isso sua presença vem se destacando entre os processos jurídicos, inclusive trazendo para o direito mais um ramo de estudo, o direito digital, uma nova matéria de lei.

Este tem sido o entendimento dos Tribunais acerca do uso das redes sociais com meio de prova, vejamos:

CIVIL. PROCESSO CIVIL. INDEFERIMENTO DE PROVA TESTEMUNHAL. RESPONSABILIDADE CIVIL. DANOS MORAIS. PUBLICAÇÃO EM FÓRUNS DE DISCUSSÕES E REDES SOCIAIS 1. A dilação probatória é útil tão-somente ao convencimento do julgador, que não é obrigado a produzir prova considerada inútil para tal fim ou meramente protelatória. 2. Atualmente, há uma grande exposição da vida privada nas redes sociais, o que, apesar de natural, deve ser realizado com cautela. Tendo em vista que a liberdade de manifestação de pensamento e expressão não é absoluta, exige-se que o indivíduo tenha o cuidado ao emitir opiniões, para que não se tornem difamatórias ou injuriosas, sob pena de configurar um ato ilícito e causar prejuízos a terceiros. 3. As publicações em fóruns de discussões e redes sociais, imputando fatos ofensivos e prejudiciais à honra de terceiros, é passível de indenização por danos morais. 4. Negado provimento ao recurso. (Grifei) (TJDF. Processo: APC 20100111943816 DF 0062720-82.2010.8.07.0001. Órgão Julgador: 6a Turma Cível. Relator (a): ESDRAS NEVES. Julgamento: 05/11/2014. Publicado no DJE : 18/11/2014 . Pág.: 208.)

AGRAVO DE INSTRUMENTO. ALIMENTOS PROVISÓRIOS EM FAVOR DO FILHO MENOR. Considerando a (a) necessidade presumida do beneficiário da pensão, decorrente da menoridade - 3 anos; (b) a ausência de elementos para aferir a real capacidade financeira do alimentante, e (c) os sinais de riqueza demonstrados na rede de relacionamento Facebook, adequado fixar os alimentos provisórios em $80 \%$ do salário mínimo. DERAM PARCIAL PROVIMENTO. UNÂNIME. (Agravo de Instrumento No 70065364986, Oitava Câmara Cível, Tribunal de Justiça do RS, Relator: Luiz Felipe Brasil Santos, Julgado em 03/09/2015). (TJ-RS - AI: 70065364986 RS, Relator: Luiz Felipe Brasil Santos, Data de Julgamento: 03/09/2015, Oitava Câmara Cível, Data de Publicação: Diário da Justiça do dia 08/09/2015). 
Com relação a aceitação e eficácia desse meio de prova no Poder Judiciário, é relevante lembrar da lei 11.419/2006 que trata do Processo Eletrônico, sistema implantado no Judiciário, que recepciona as provas digitais, assim como o artigo 225 do Código Civil:

Art. 225. As reproduções fotográficas, cinematográficas, os registros fonográficos e, em geral, quaisquer outras reproduções mecânicas ou eletrônicas de fatos ou de coisas fazem prova plena destes, se a parte, contra quem forem exibidos, não thes impugnar a exatidão (BRASIL, CÓDIGO CIVIL, 2002).

O Código de Processo Civil também aceita as provas eletrônicas desde que preservem a integridade da prova desde o momento em que foi colhida até sua apresentação, para que haja certeza que não foi obtida por meio ilícito.

A utilização de documentos eletrônicos está disposta no art. 439: “Art.439. A utilização de documentos eletrônicos no processo convencional dependerá de sua conversão à forma impressa e de verificação de sua autenticidade, na forma da lei" (BRASIL, CÓDIGO DE PROCESSO CIVIL, 2015).

O documento eletrônico deve ser convertido de acordo com a forma expressa. Caso não seja convertido, o juiz apreciará o seu valor probante, assegurando às partes o acesso ao seu teor.

Além disso, existem documentos assinados digitalmente, o que presume que o documento tenha veracidade. A Medida Provisória 2.200/2001 criou a Infraestrutura de Chaves Públicas Brasileiras (ICP), que tem como objetivo dar autenticidade e validade jurídica aos documentos eletrônicos assinados por meio de certificado digital. Se o documento não for munido de assinatura digital conforme o ICP, pode-se tornar material de perícia para verificar sua integridade.

As redes sociais, então, ficam classificadas como meio de prova, tendo em vista que as situações expostas na internet podem comprovar o fato que seja objeto de uma lide, desde que a prova seja obtida por meio lícito, sem lesionar o direito à privacidade de outrem.

A comprovação de um fato por uma rede não responsabiliza a plataforma pela exposição da pessoa, quando esta escolhe postar na rede tal fato, significa que não tem receio algum de que as pessoas vejam aquilo, por esse motivo, os prints tem sido a principal prova juntada nos autos, em casos diversos.

A afirmação de que o Poder Judiciário vem se modernizando junto com a sociedade é verdadeira. Conforme visto anteriormente, o processo digital abriu caminhos para o acesso à justiça e trouxe novas situações ao processo.

Os princípios constitucionais relacionados ao uso das redes sociais são o da liberdade de expressão e do direito à privacidade. A nossa Constituição Federal classificou como um dos direitos fundamentais para o cidadão brasileiro, a liberdade de expressão, disposto no artigo $5^{\circ}$ em seus incisos IV, VIII, IX e XVI.

É direito da pessoa expressar-se, ressalvada as situações em que ferir a outrem, na medida em que o direito de uma pessoa termina quando começa o de outra, o respeito e o equilíbrio são a base para o exercício da livre expressão. 
Com o surgimento das redes sociais e o contexto que se formou com seu uso pela sociedade, os usuários usam essa plataforma como local de livre expressão sem sequer lembrar-se da existência da proteção constitucional dessa liberdade e das consequências das palavras lançadas na rede.

O exercício do direito à liberdade de expressão deve, então, ser dotado de cautela, de forma que não chegue a ferir a honra de outra pessoa. É por esse motivo que o cuidado com as postagens feitas nas redes sociais deve ser reforçado, de forma que não se tem dimensão do que uma simples postagem poderá acarretar a seu autor.

A privacidade consiste em algo que o indivíduo quer reservar e guardar para si, mas em um caráter diferente da intimidade, a vida privada pode se referir a momentos, família ou algo compartilhado, mas sem intenção de exposição.

A intimidade tem caráter individual, com o objetivo de que outras pessoas não tenham conhecimento daquilo. Pode-se dizer que o direito à intimidade é algo que deve ser mantido em sigilo, por isso a violação desse direito é tão devastadora para a pessoa lesada.

Por esses motivos, as redes sociais criaram uma política de privacidade interna, para assegurar que os dados pessoais, conversas e conteúdos compartilhados pelo usuário estejam protegidos.

O direito à privacidade na sociedade desenvolvida em que vivemos enfrenta grandes desafios. Cada dia se descobre novas maneiras de violação do direito, e a busca para a sua proteção tornou-se incessável, na medida em que deve avançar junto com a tecnologia e a mutação social.

\subsection{Direito Digital e Leis Específicas}

O direito digital é a evolução de todos os ramos do direito, adaptando-os ao ordenamento jurídico existente a tecnologia e aos meios de comunicação atuais. Tem como um de seus pilares, o direito à informação, essa garantia constitucional está relacionada com a dignidade da pessoa humana, pois o acesso à informação interfere na qualidade de vida do indivíduo.

É evidente que a internet é fonte de informação sobre inúmeros assuntos, o que fez o direito digital ter amplificado sua matéria para as relações comerciais e, ainda, sobre a responsabilização civil dentro da rede.

Para que houvesse equilíbrio no uso deste universo desconhecido, criou-se uma ciência que abrangeria as relações entre princípios, direito e informática. A tecnologia popularizou e facilitou o acesso à informação pela sua agilidade, tanto para relações pessoais, quanto para relações corporativas.

A Constituição Federal, em seu artigo 24, inciso IX, prevê a competência da União, Estados e Distrito Federal a legislar sobre a tecnologia e, ainda, no artigo 218, assegura que o Estado deve promover e incentivar a capacitação científica e tecnológica e a inovação.

A liberdade de expressão também é prevista constitucionalmente no artigo $5^{\circ}$, inciso IX, mas determina que ao expressar-se, o indivíduo deve ter responsabilidade, observando a boa-fé e os bons costumes. 
A proteção da sociedade digital no tocante a privacidade se faz necessária, seus direitos e obrigações na internet devem ser claramente especificados para que o ambiente tecnológico seja seguro para todos que o utilizam.

O direito digital nada mais é que a evolução do próprio direito com a sociedade, formando um conjunto de normas que regulam as relações estabelecidas por meio digital, que tenham como objeto matéria de direito.

No Brasil, não existe um Tribunal com a competência de julgar conflitos decorrentes especificamente desta matéria, mas, por outro lado, na Polícia Civil existem delegacias especializadas em crimes cibernéticos, bem como há leis que dispõem sobre situações que tipificam crime, por exemplo, a Lei 12.737/2012, sancionada em 30 de novembro de 2012, popularmente conhecida como "Lei Carolina Dieckmann". Esta lei criminaliza a invasão de dispositivo informático alheio a fim de obter, adulterar ou destruir dados ou informações sem autorização do titular.

A lei do Marco Civil da Internet foi um grande avanço do direito digital no Brasil, bem como a recente criação da Lei Geral de Proteção de Dados Pessoais (13.709/2018), que derivou da necessidade da sociedade digital ter mais segurança no compartilhamento de dados pessoais.

De fato, o direito digital se comunica com inúmeras faces do direito, por isso sua aplicação é relativa quanto à matéria abordada. Independentemente disso, as leis que tratam destas relações necessitam evoluir juntamente com os avanços tecnológicos para que o direito da sociedade esteja sempre resguardado na esfera virtual.

Podemos verificar que, independentemente de lei, e diante da imensidão virtual, cabe ao usuário utilizar este meio de informação e comunicação de forma ética, com boa-fé, sob pena de responder juridicamente por seus atos.

\subsubsection{MARCo CIVIL DA INTERNET (LEI No 12.965/14)}

A lei do Marco Civil da Internet foi fundamental para o início da legislação sobre direito digital, sendo considerada a Constituição da Internet, nela encontramos direitos e deveres, garantias e princípios que regem o uso da internet no Brasil, além de zelar pela privacidade dos usuários da rede.

O artigo 10 da lei do Marco Civil da Internet 12.695/2014 disserta sobre a guarda e disponibilização dos registros da internet, bem como de dados pessoais, devendo atender a preservação da intimidade, da vida privada, da honra e da imagem das partes diretamente ou indiretamente envolvidas, permitindo a utilização de mecanismos que preservam o adequado uso das provas eletrônicas no processo.

\subsubsection{Lei Geral de ProteÇão de Dados No 13.709/2018}

A Lei Geral de Proteção de Dados Pessoais (13.709/2018) é a mais recente legislação dentro do direito digital, teve como base o Regulamento Geral de Proteção de Dados Pessoais Europeu número 679 de 2016, e juntamente com a Lei do Marco Civil da Internet, tem como objetivo proteger pessoas físicas que têm seus dados pessoais circulando na rede, trazendo liberdade, segurança, justiça e transparência no tratamento dos dados pessoais e principalmente, o equilíbrio nas relações digitais. 
O processo de aprovação da Lei de Proteção de Dados teve prioridade depois que, coincidentemente, ocorreram diversos vazamentos de informações pessoais por meio de redes como Facebook, no período de eleições nos Estados Unidos, o fato tomou uma enorme proporção diante da quantidade de pessoas que foram lesionadas. A lei caracterizou seu objeto de proteção, em especial os dados pessoais e sensíveis, no artigo $5^{\circ}$ e seus incisos:

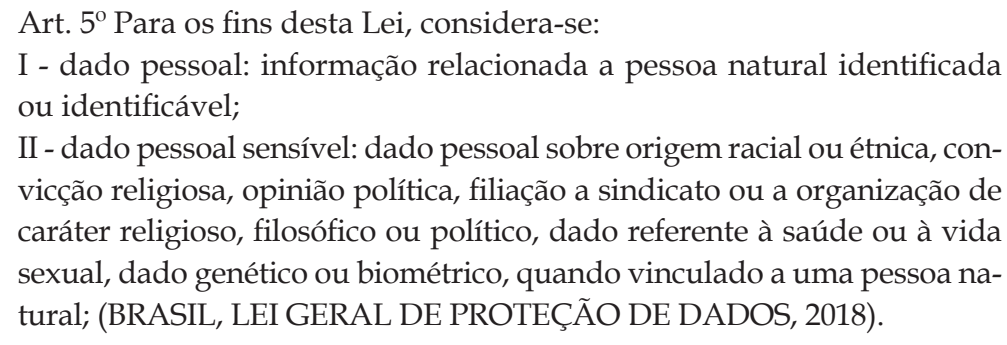
sexual, dado genético ou biométrico, quando vinculado a uma pessoa natural; (BRASIL, LEI GERAL DE PROTEÇÃO DE DADOS, 2018).

Inicialmente, a mudança considerada de maior impacto é a necessidade de autorização para a coleta de dados, disposto no artigo $7^{\circ}$ da referida lei: “Art. $7^{\circ} \mathrm{O}$ tratamento de dados pessoais somente poderá ser realizado nas seguintes hipóteses: I - mediante o fornecimento de consentimento pelo titular;" (BRASIL, LEI GERAL DE PROTEÇÃO DE DADOS, 2018). Tal previsão traz a ideia de que a parte terá conhecimento de que seus dados serão utilizados por tal empresa.

Ainda tratando do consentimento do compartilhamento dos dados, o artigo $9^{\circ}$ da referida Lei estabelece que as informações fornecidas ao titular dos dados devem ser em respeito ao princípio do livre acesso, transparentes, adequadas e claras, de forma que facilite o entendimento do titular.

Tais disposições demonstram o avanço que a lei trará à relação entre o indivíduo e a empresa que solicitar seus dados, uma relação de confiança, em respeito aos princípios da boa-fé e da privacidade, protegendo tanto a empresa, quanto a sociedade.

No ramo empresarial, haverá a necessidade de adequação das empresas para que garantam a transparência e a informação das pessoas que forneceram seus dados, de forma que compreendam a situação. Essa disposição será aplicada também para os consumidores que utilizam a internet como meio de consumo, uma vez que concedem até dados bancários para efetuar as compras.

Tamanha é a proteção trazida pela lei, que não deixou de criar sanções para responsabilizar aquele que causar dano a outrem, fixando até mesmo o dever de indenização pelos danos, conforme disposto no artigo 42 da Lei 13.709/18.

Antes que a lei originária entrasse em vigor, foi aprovada a Medida Provisória $n^{\circ} 869$ de 2018, que alterava a Lei n ${ }^{\circ}$ 13.709/2018, Lei de Proteção de Dados para a criação da Autoridade Nacional de Proteção de Dados, sendo incluída na estrutura da Presidência da República, para que houvesse maior fiscalização das empresas, trazendo sanções, direitos e deveres, o que torna a Lei de Proteção de Dados mais efetiva. 
A Lei Geral de Proteção de Dados entrou em vigor em setembro de 2020, em meio a muitas discussões, afirmando que as empresas brasileiras ainda não estariam prontas para se adaptarem às novas regras de privacidade.

Em razão da pandemia do covid-19, em abril de 2020 foi aprovada a Medida Provisória 959/2020, agora convertida em Lei $\mathrm{n}^{\mathrm{o}}$ 14.058/2020, que dentre suas disposições, adiou a vigência da Lei Geral de Proteção de Dados, no tocante às sanções, que passarão a viger a partir de agosto de 2021.

A Medida Provisória gerou grande repercussão tendo em vista que, em tempos de isolamento social, o uso dos dados pessoais na internet e nas redes sociais aumentou drasticamente e o adiamento da vigência da Lei 13.709/18 poderia deixar a população ainda mais vulnerável.

\section{POLÍTICA DE PRIVACIDADE DAS REDES SOCIAIS}

No tocante à política de privacidade nas redes sociais, cada rede conta com uma política interna de privacidade. Um dos requisitos para o ingresso na rede é o cadastro, o qual solicita dados pessoais entre outros que formam o perfil do usuário.

Todo conteúdo postado nas redes sociais sobre o cotidiano, viagens, restaurantes, roupas, política, enfim, cada informação adicionada ao perfil do usuário fica disponível àqueles que a pessoa deseja e autoriza compartilhar.

Por esse motivo, as redes atualizam constantemente suas políticas, pelo grande armazenamento de dados que detém, a fim de evitar eventuais inconveniências com vazamento de dados pessoais. A política de privacidade do Facebook, que também é responsável pelas redes sociais Instagram, WhatsApp e Messenger, informa sobre o compartilhamento dos dados pessoais, disponível a todos os usuários cadastrados, que os dados fornecidos pelo usuário, juntamente com o conteúdo compartilhado, criam uma espécie de filtro, e faz com que a rede realize ações que apresentem ao usuário conteúdos compatíveis com o seu perfil.

Por outro lado, percebemos que com essas informações a rede cria um sistema de vigilância sobre o seu usuário. Tudo aquilo que é conversado, uma foto publicada em algum local, servem como matéria para trazer à pessoa assuntos de seu interesse.

A política de privacidade possibilita que o usuário escolha se seu perfil será público ou privado. Aquele que escolhe ter seu perfil público está ciente que qualquer pessoa, em qualquer lugar do mundo, poderá acessar o conteúdo compartilhado, até mesmo as informações pessoais adicionadas na rede.

Para garantir o consentimento do usuário, o Facebook esclarece acerca do perfil público em sua política:

Informações públicas podem ser vistas por qualquer pessoa, dentro e fora de nossos Produtos, inclusive se essa pessoa não tiver uma conta. Isso inclui seu nome de usuário do Instagram; qualquer informação que você compartilha publicamente; informações de seu perfil público no Facebook; e o conteúdo que você compartilha em uma Página do Facebook, conta pública do Instagram ou qualquer outro fórum públi- 
co, como o Marketplace do Facebook. Você, outras pessoas que usam o Facebook e o Instagram e nós podemos fornecer acesso ou enviar informações públicas para qualquer pessoa dentro e fora de nossos Produtos, inclusive em outros Produtos das Empresas do Facebook, em resultados de pesquisas ou por meio de ferramentas e APIs. É possível também visualizar, acessar, compartilhar novamente ou baixar informações públicas por meio de serviços de terceiros, como mecanismos de pesquisa, APIs e mídia offline como a TV, e por meio de aplicativos, sites e outros serviços que se integram a nossos Produtos. [...] Informações que você compartilha que são sempre públicas: algumas das informações que você forneceu ao preencher seu perfil são públicas, como faixa etária, idioma e país. Também usamos uma parte do seu perfil (chamada de perfil público) para ajudar a conectar você com seus amigos e familiares. O perfil público contém seu nome, gênero, nome de usuário e número de identificação do usuário (número da conta), foto do perfil, foto da capa e redes. Essas informações também são públicas. (FACEBOOK, 2021, p. [12], grifo do autor).

Podemos verificar que os perfis públicos deixam vulneravam todas as informações da pessoa que escolhe utilizá-lo. Cumpre ressaltar que o perfil público é uma escolha do usuário, e não uma imposição da rede.

Ainda assim, até mesmo o perfil privado deixa algumas informações ao alcance de outros usuários, para que as redes possam conectar as pessoas que tenham alguma ligação com o perfil, sendo de interesses até parentesco e amizade, as poucas informações disponibilizadas no perfil privado viabilizam que essa apuração seja feita.

A política de privacidade se preocupa com a segurança das informações e a forma de intervenção da plataforma, quando necessário, de modo que a intervenção nos casos de atividades ilegais e fraudulentas assegura ao usuário que, se houver lesão a algum direito por meio dessa plataforma, poderá ter auxílio desta, mencionando até mesmo o auxílio em casos que houver solicitação judicial para acesso das informações, colaborando com o devido processo legal.

Ainda que haja toda a previsão de segurança das informações contidas nas redes sociais, a política de privacidade não prevê, em seu teor, o uso das postagens feitas pelos navegantes como prova em processo judicial.

Cumpre ressaltar que as redes sociais com maior número de usuários no mundo todo fazem parte do grupo do Facebook. Os aplicativos WhatsApp e Instagram, integrados ao Facebook, respondem à mesma política de privacidade.

Um diferencial do WhatsApp é a criptografia das mensagens, um sistema que permite somente às partes terem acesso às mensagens enviadas, nem mesmo o aplicativo pode acessar o conteúdo da conversa. Vejamos a informação repassada aos usuários sobre a criptografia:

A criptografia de ponta a ponta do WhatsApp é usada quando você conversa com outra pessoa no WhatsApp Messenger. A criptografia de ponta a ponta garante que somente você e a pessoa com quem você 
está se comunicando podem ler ou ouvir as mensagens trocadas. Ninguém mais terá acesso a elas, nem mesmo o WhatsApp. Suas mensagens estão seguras com cadeados e somente você e a pessoa com quem você está se comunicando possuem as chaves especiais necessárias para destrancá-los e ler suas mensagens. Todo esse processo acontece automaticamente: não é necessário ativar configurações ou estabelecer conversas secretas especiais para garantir a segurança de suas mensagens. (WHATSAPP, 2021, p. [1]).

Os prints de perfis estão cada dia mais presentes nos processos judiciais, nos quais as redes são usadas como meio de prova. Dependendo da publicação do usuário, é possível provar sua localização no momento de um fato discutido na lide, alguma frase que pode ter lesionado a outrem, até mesmo a condição financeira de uma pessoa pode ser comprovadas por meio de postagens, feitas pela própria pessoa em seu perfil, com acesso livre.

A rede não pode ser responsabilizada pelas consequências jurídicas de uma postagem feita de livre e espontânea vontade pelo usuário. A invasão de privacidade só ocorre caso haja o vazamento de informações, fotos e conteúdos particulares do usuário. O que não se aplica ao caso mencionado no começo deste parágrafo, tendo em vista que a postagem é um ato de vontade, personalíssimo, com o objetivo de expor tal situação aos outros usuários, seja de sua rede privada de amigos ou a todos que tiverem acesso.

Atualmente, o Facebook adicionou em sua política de dados um aviso de privacidade, informando sobre as alterações das disposições em razão da Lei 13.709/18.

Ainda assim, o Facebook e as demais redes sociais não dispõem em suas políticas internas sobre sua responsabilização acerca dos vazamentos de dados. Por esse motivo, a Lei Geral de Proteção de Dados (Lei 13.709/18) é um marco importante para internet, tendo em vista que trouxe a proteção que os usuários das redes sociais necessitavam.

\section{CONSIDERAÇÕES FINAIS}

No mundo tecnológico em que vivemos hoje, a internet se tornou a principal forma de comunicação e de acesso à informação e, consequentemente, o mundo jurídico sofreu alterações para que pudesse acompanhar o desenvolvimento da sociedade.

Foram criadas leis que protegem os dados pessoais que são disponibilizados na rede pelos internautas, visando a proteção ao direito à privacidade, à liberdade de expressão e à dignidade da pessoa humana, para evitar que o indivíduo lesionado na esfera on-line pudesse recorrer ao Judiciário para a reparação do dano.

Sanados os pontos de proteção à pessoa na internet, nos deparamos com um quadro diferente no processo civil, no momento em que a maioria das provas acostadas aos autos são retiradas de redes sociais. As pessoas criam perfis nas redes e postam tudo aquilo que lhes interessam, como suas opiniões, pensamentos, afazeres do dia a dia, viagens e alguns mostram até uma vida que não condiz com a realidade. 
Por esse motivo, as redes sociais começaram a dominar os processos como um novo meio de prova. As postagens feitas começaram a ter relação com fatos discutidos juridicamente, como, por exemplo, união estável, condição financeira e localização. Tudo o que era postado na internet e levado a juízo poderia comprovar fatos de direito.

A aceitação das provas obtidas por meio das redes sociais é evidente, dificilmente encontra-se um processo que não tenha como prova alguma página da internet que corrobore com os fatos alegados, e é pacífica a aceitação dos documentos eletrônicos no processo.

Ainda que não sejam dotados de autenticidade, não podemos nos esquecer da presunção de veracidade e, ainda, do livre convencimento motivado do juiz, ou seja, caso o magistrado entenda que a prova foi obtida por meio lícito e corresponde a um fato controvertido da lide, terá eficácia para a comprovação de um fato.

As redes sociais podem nos trazer muitos benefícios, comunicação, lazer, mas também, nos casos em que outrem é lesionado através da rede, podem trazer consequências jurídicas.

A tecnologia ainda ocasionará muitas mutações para a sociedade, estamos apenas no início deste processo e, portanto, devemos ser cautelosos quando se trata de exposição na internet, tanto no tocante aos dados pessoais, quanto à própria vida pessoal, e ao mesmo tempo, utilizar as redes para aquilo que pode nos trazer um grande conteúdo para o conhecimento.

\section{REFERENCIAS}

BRASIL. Código Civil. Brasília, 2002. Disponível em: http://www.planalto.gov.br/ccivil_03/leis/2002/110406.htm. Acesso em: 07 out. 2020.

BRASIL. Código de Processo Civil. Brasília, 2015. Disponível em: http://www.planalto. gov.br/ccivil_03/_ato2015-2018/2015/lei/113105.htm. Acesso em: 07 out. 2020.

BRASIL, Colégio notarial. Ata notarial, 2021. Disponível em: https://www.cnbsp.org. $\mathrm{br} /$ ?url_amigavel=1\&url_source=paginas\&id_pagina $=6002 \& \mathrm{lj}=1366$. Acesso em: 20 jan. 2021.

BRASIL. Constituição da República Federativa do Brasil de 1988. Brasília. Disponível em: http://www.planalto.gov.br/ccivil_03/constituicao/constituicao.htm. Acesso em: 07 out. 2020.

BRASIL. Lei $\mathrm{n}^{\circ} 12.965$, de 23 de abril de 2014. Estabelece princípios, garantias, direitos e deveres para o uso da Internet no Brasil. Marco civil da internet. Brasília. Disponível em: http://www.planalto.gov.br/ccivil_03/_ato2011-2014/2014/lei/112965.htm. Acesso em: 20 jan. 2021.

BRASIL. Lei ${ }^{\circ}{ }^{13.709 / 2018}$. Lei Geral de Proteção de Dados Pessoais. 2018. Disponível em: http://www.planalto.gov.br/ccivil_03/_ato2015-2018/2018/lei/L13709.htm Acesso em: 11 jan. 2021. 
BRASIL. Medida Provisória n ${ }^{\circ}$ 959, de 29 de abril de 2020. Estabelece a operacionalização do pagamento do Benefício Emergencial de Preservação do Emprego e da Renda e do benefício emergencial mensal de que trata a Medida Provisória $n^{\circ}$ 936, de $1^{\circ}$ de abril de 2020, e prorroga a vacatio legis da Lei $\mathrm{n}^{\circ} 13.709$, de 14 de agosto de 2018, que estabelece a Lei Geral de Proteção de Dados Pessoais - LGPD. [S. 1.], 29 abr. 2020. Disponível em: http:/ / www.planalto.gov.br/ccivil_03/_ato2019-2022/2020/mpv/mpv959.htm. Acesso em: 12 ago. 2020.

BRASIL,Projeto de Lei: altera a Lei $\mathbf{n}^{0}$ 13.709, de 2018, prorrogando a data da entrada em vigor de dispositivos da Lei Geral de Proteção de Dados Pessoais - LGPD - para 15 de agosto de 2022. 2019. Disponível em: https:/ / www.camara.leg.br/proposicoesWeb/fichadetramitacao?idProposicao=2227704. Acesso em: 18 jan. 2021.

FACEBOOK. Aviso de privacidade. 2021. Disponível em: https://www.facebook.com/ policy.php. Acesso em: 23 jan. 2021.

FACEBOOK. Política de privacidade.2018. Disponível em: https:/ / www.facebook.com/ policy.php. Acesso em: 23 nov. 2019.

PECK, Patricia Pinheiro. \#Direito digital. 6. ed. São Paulo: Saraivajur, 2016.

PECK, Patricia Pinheiro. Proteção de dados pessoais: comentários à Lei n. 13.709/2018 LGPD. São Paulo: Saraivajur, 2018.

THEODORO JÚNIOR, Humberto. Curso de direito processual civil. 59 ed. São Paulo: Forense, 2018.

TRATADO INTERNACIONAL. CONVENÇÃO AMERICANA DE DIREITOS HUMANOS. Pacto de San José da Costa Rica.1969. Disponível em: http:/ / www.pge.sp.gov.br/ centrodeestudos/bibliotecavirtual/instrumentos/sanjose.htm_Acesso em: 08 nov. 2019.

WHATSAPP. Criptografia de ponta. 2021 Disponível em: https://faq.whatsapp.com/general/28030015/?lang=pt_br. Acesso em: 23 jan. 2021. 